\title{
Da Química à Bioquímica: O Percurso Científico de Kurt Jacobsohn em Portugal (1929-1979)
}

\author{
Isabel Amaral *
}

\begin{abstract}
A
ciência é o resultado da sua história. É justamente por isso que nos propomos revisitar a obra de Kurt Paul Jacobsohn (1904-1991), um cientista alemão que realizou em Portugal grande parte da sua carreira científica, tornando-se assim uma figura da história da ciência portuguesa que importa conhecer e divulgar.

Kurt Jacobsohn emigrou para Portugal em 1929 e aqui permaneceu até 1979, data em que se retirou para Israel. Criou em Portugal uma escola de investigação - sediada num instituto de investigação de gestão privada, o Instituto de Investigação Científica Bento da Rocha Cabral - que lhe permitiu instituir a bioquímica como nova área disciplinar, tendo acrescentado à dimensão fisiológica da bioquímica portuguesa a dimensão química.

Iniciou a primeira página da história da bioquímica em Portugal com um programa de investigação inovador centrado na enzomologia e no estudo do metabolismo intermediário, a partir do qual estabeleceu uma rede de interesses científicos que se expandiram do instituto que o acolheu para a Faculdade de Ciências da Universidade de Lisboa, onde a bioquímica acabaria por se consolidar como área científica independente em 1982.
\end{abstract}

\section{INTRODUÇÃO}

O legado de Kurt Jacobsohn para a história da bioquímica em Portugal está intimamente associado à história do Instituto de Investigação Científica Bento da Rocha Cabral, criado por vontade testamentária de Bento da Rocha Cabral (1847-1921) ${ }^{1}$. Foi com grande surpresa que os seus testamenteiros se viram confrontados com a disposição que determinava a criação de um instituto de investigação em Lisboa, a exemplo dos institutos Rockefeller e Carnegie, nos Estados Unidos, confiado a Ferreira de Mira $^{2}$ $[1,2]$, o instituto que recebeu o seu nome, Instituto de Investigação Científica Bento da Rocha Cabral (IRC) [3, 4] - Figura 1.

Em 1925, iniciaram-se os trabalhos de investigação no instituto e em 1929 estavam definidas as áreas de investigação, com os respectivos espaços laboratoriais: a fisiologia, a microbio-

\footnotetext{
* Departamento de Ciências Sociais Aplicadas, Faculdade de Ciências e Tecnologia, Universidade Nova de Lisboa, 2829-516 Caparica
}

logia, a histologia e a química biológica. A secção de química biológica foi a última a ser instalada porque a investigação experimental em Portugal nesta área era considerada incipiente, ao contrário da Alemanha, onde o estudo dos processos metabólicos estava nesta altura em pleno apogeu. Ferreira de Mira, na qualidade de director do IRC, deslocou-se a Berlim, ao Kaiser
Wilhelm-Institut für Biochemie, então sob a direcção de Carl Neuberg ${ }^{3}[5$, 6 ], a quem pediu que lhe indicasse um dos seus colaboradores que pudesse instalar em Portugal um laboratório de bioquímica no Instituto Rocha Cabral. Neuberg indicou-lhe Kurt Jacobsohn (Figura 2), que aceitou o convite. Veio para Portugal no início da sua carreira científica, com apenas 25 anos e

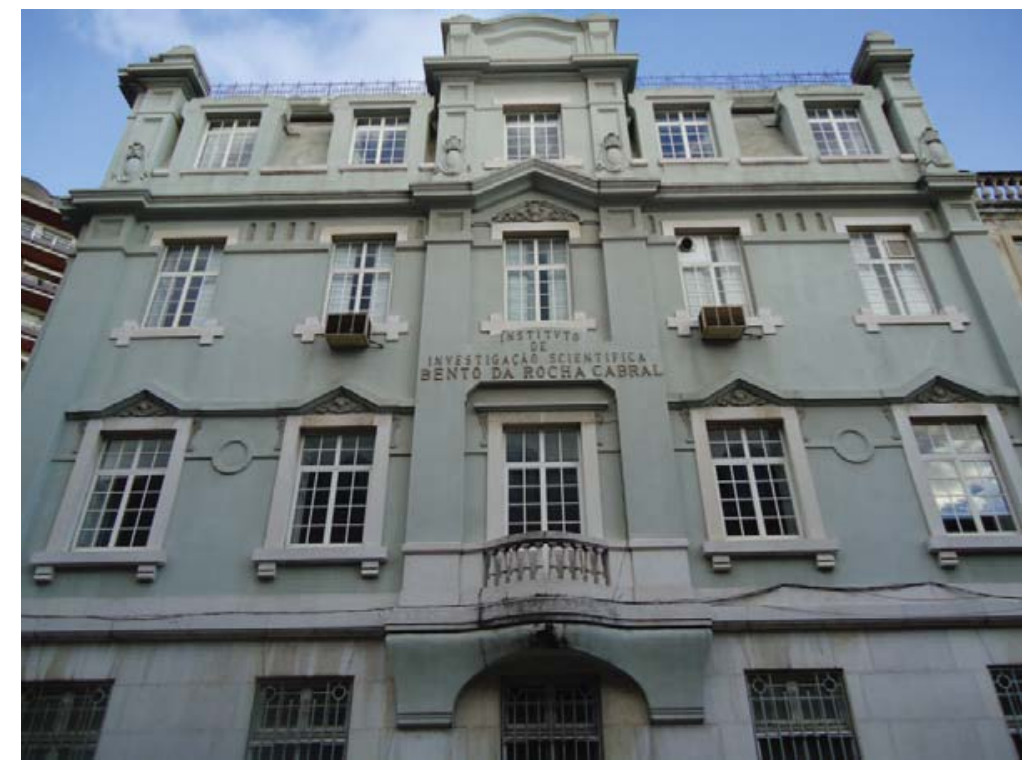

Figura 1 - Fotografia da fachada principal do Instituto de Investigação Científica Bento da Rocha Cabral 
recém-casado. Realizou a viagem de núpcias a caminho de Portugal, juntamente com os seus pais $[5,6]$.

Ferreira de Mira e a administração do IRC estabeleceram com ele um contrato por um período de quatro anos, período após o qual, se tornou vitalício.

Kurt Jacobsohn obteve deste modo uma situação financeira que lhe permitia encarar o futuro com alguma esperança, dado já ser evidente na época o processo que conduziria ao extermínio de judeus pelo III Reich.

\section{Revisitando a Vida e Obra de KURT JACOBSOHN}

Kurt Jacobsohn, de ascendência judaica, nasceu em Berlim a 31 de Outubro de 1904. Iniciou a sua carreira de químico no ensino secundário no Luisen-Gymnasium zu Berlin. Ingressou na Friedrich-Wilhelms-Universität zu Berlin em 1923 e, em 1924, fez o exame de admissão aos Institutos de Química Orgânica e de QuímicaFísica nesta universidade. Entre 1926 e 1928, preparou a tese de doutoramento sob orientação de Carl Neuberg. Em 1927 tinha já sido nomeado por Carl Neuberg como assistente do instituto de investigação que dirigia em Berlim, funções que desempenhou até Abril de 1929 [5, 6]. A partir desta

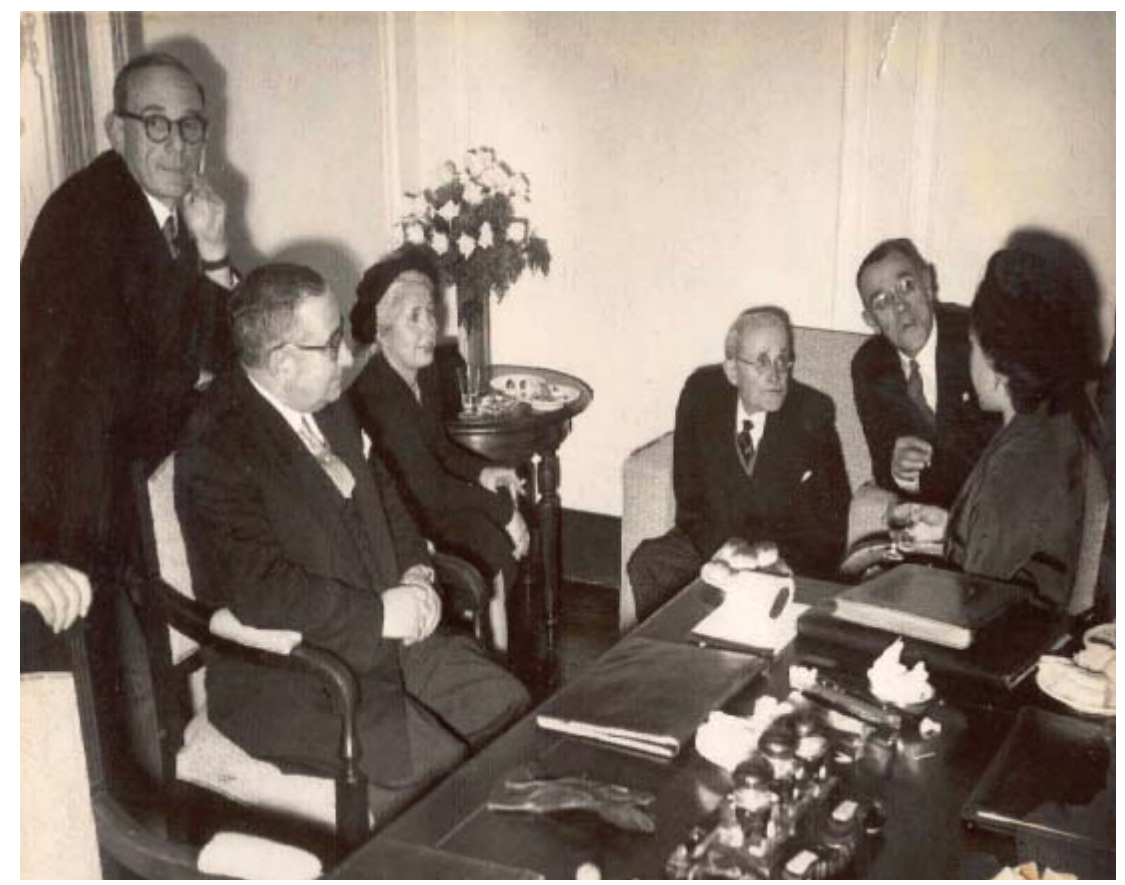

Figura 2 - Fotografia tirada na Sala da Direcção do IRC, no dia da Comemoração dos 25 anos do Instituto, em 1951, onde se identificam Kurt Jacobsohn em pé à esquerda, Joaquim Fontes e Liesel Jacobsohn (sua esposa) em baixo, e à esquerda, Ferreira de Mira altura desenvolveu toda a sua carreira científica e académica em Portugal.

Em 1935 adquiriu a nacionalidade portuguesa e recebeu equivalência do grau de Doutor conferido pela Universidade de Berlim ao de Doutor em Ciências Físico-Químicas pela Universidade de Lisboa. A partir desta data ingressou então na Faculdade de Ciências por proposta de D. António Pereira Forjaz. Foi responsável pela regência de várias disciplinas: 0 Curso Teórico de Noções Gerais de Química-Física (1936-1942), o curso de Análise Química (1942-1947) e Química Orgânica (1942) e o curso de Química Médica (1948-1954). Tornouse professor catedrático de Química Orgânica em 1955 e, em 1974, abandonou a carreira docente universitária após jubilação [5, 6].

Foi secretário, bibliotecário, director do laboratório de química da Faculdade de Ciências e vice-reitor da Universidade de Lisboa entre 1966 e 1970. Como professor, publicou vários livros de texto de química em colaboração com docentes da Faculdade de Ciências e com investigadores do Instituto Rocha Cabral [5, 6].

Kurt Jacobsohn foi o principal impulsionador da bioquímica e "entre nós sempre lutou pela criação dessa cadeira [a bioquímica] e, depois dela

240 artigos, reflecte o grande número de publicações realizadas em periódicos estrangeiros especializados em enzimologia e em bioquímica, como podemos visualizar no Gráfico 2 .

Ao analisarmos a actividade científica de Kurt Jacobsohn, facilmente nos apercebemos das estreitas ligações internacionais que este mantinha, em particular com a Alemanha. É notória a sua influência no estabelecimento de canais de comunicação privilegiados com os principais periódicos especializados em bioquímica e em enzimologia, onde difundiu a obra da sua escola.

\section{Um OlHAR PELA InVEStigação}

Ao chegar a Portugal, em 1929, criou uma escola de investigação em enzimologia, dedicando-se ao estudo do metabolismo celular, com particular enfoque no estudo das enzimas in- 
tervenientes nestes processos, acompanhando as alterações conceptuais e metodológicas da disciplina a nível europeu. O programa de investigação que concebeu, baseado na tradição química alemã, faz uma abordagem molecular dos fenómenos biológicos. Inclui estudos de síntese química de diferentes compostos intervenientes em reacções catalisadas por enzimas; a análise estrutural e o estudo cinético de diversos enzimas pouco estudados na época; e ainda o estudo do metabolismo celular, procurando justificar o modo de acção dos enzimas do ponto de vista da regulação metabólica. Para a concretização destes objectivos, utilizou técnicas específicas de doseamento de diferentes macromoléculas biológicas, algumas delas desenvolvidas pela própria "escola", outras optimizadas. Dentre este conjunto de técnicas salienta-se a polarimetria, a fluorimetria, a dispersão óptica rotatória, a espectropolarimetria e a aplicação de radioisótopos como indicadores em estudos bioquímicos $[5,6]$.

Entre os biocatalisadores conhecidos na época escolheu prioritariamente um grupo de enzimas, as alcenoica$\mathrm{ses}^{4}$, cujas características os tornam acessíveis a estudos cinéticos. Estes enzimas catalisam reacções que estabelecem equilíbrios químicos simples e acessíveis à análise, porque neles estão representados tanto os reagentes como os produtos da reacção em condições apreciáveis, e, além disso, como são compostos opticamente activos, são facilmente doseados. Desta forma era possível estudar o problema tanto do ponto de vista estático como dinâmico e, ao mesmo tempo, confrontar os valores cinéticos encontrados com as condições energéticas do sistema, de acordo com a segunda lei da termodinâmica $[5,6]$.

O desenvolvimento da enzimologia foi lento na história da bioquímica. Embora algumas contribuições para o estudo de enzimas tenham surgido no início do século XIX, como a amilase, a pepsina, a catalase e a invertase, o que é facto é que em 1920, apenas eram conhecidos cerca de 12 enzimas que não tinham ainda sido isolados e pouco se conhecia acerca da sua natureza química e catalítica [5,

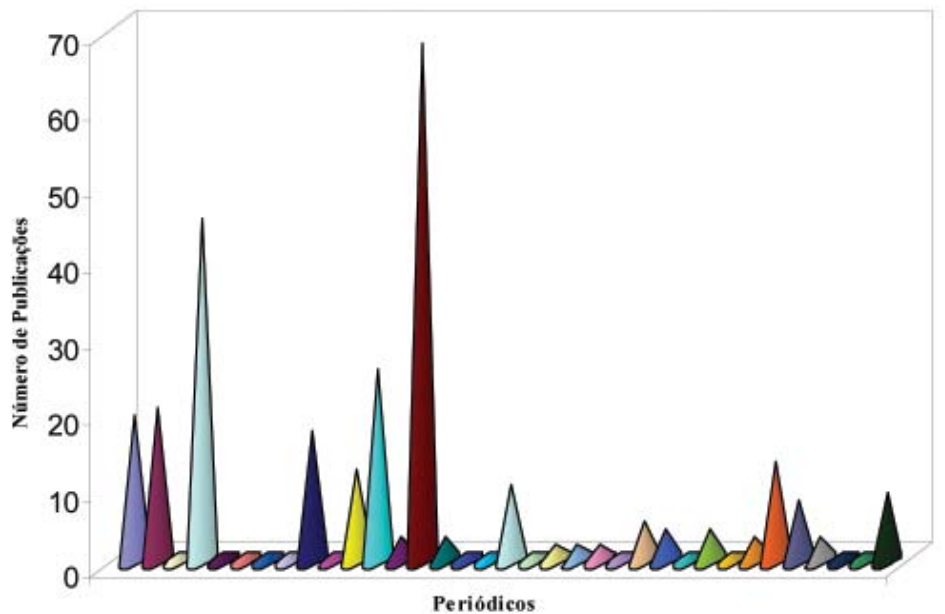

$\square$ Actualidades Biológicas

Congressos, Simpósios

$\square$ Anais Azevedos

$\square$ Archives Portugaises des Sciences Biologiques

Archives of Biochemistry

Archives of Biochemistry and Biophysics

Arzneimittel-Forschung

Berichte der Deutschen Chemischen Gesellschaft

Biochemische Zeitschrift

Boletim da Academia das Ciências

Bulletin de la Société de Chimie Biologique

口 Bulletin de la Société Portugaise des Sciences Naturelles

口Ciência

- Comptes Rendus de la Société de Biologie de Paris

Curriculos, Dissertações

Enzymologia Acta Biocatalytica

Enzymologia

Experimental Medicine and Surger

Fermentforschung

$\square$ Gazeta de Fisica

Gazeta Médica Portuguesa

International Abstracts of Biological Sciences

Publicações Particulares (IRC; Junta Investigações Ultramar)

Lisboa Médica

Medicina

Naturalia

Portugaliae Acta Biologica

Revista de Ouímica Pura e Aplicada

Revista da Faculdade de Ciências de Lisboa

Revista Portuguesa de Química

Scientia
Zeitchrify fur Anaytische Chemie

Zeitschrift fur Immunitats forschung

Obras Didácticas

Gráfico 1 - Total de Publicações de Kurt Jacobsohn efectuadas entre 1929 e 1979, distribuídas pelos vários periódicos nacionais e estrangeiros
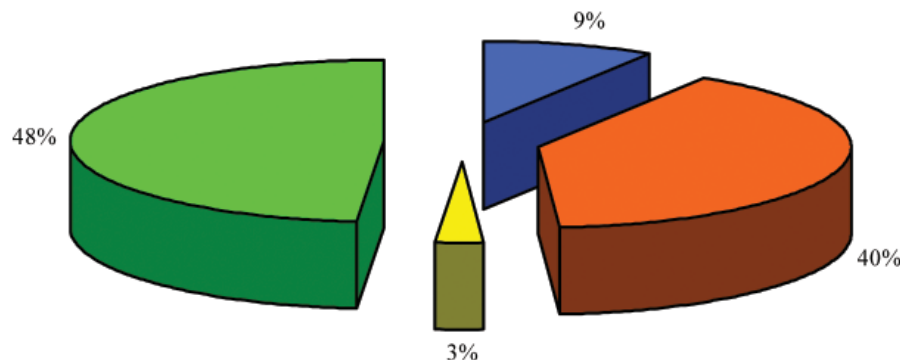

$\square$ Publicações em periódicos nacionais generalistas

$\square$ Publicações em periódicos nacionais da especialidade

$\square$ Publicações em periódicos estrangeiros generalistas

$\square$ Publicações em periódicos estrangeiros da especialidade

Gráfico 2 - As publicações totais de Kurt Jacobsohn efectuadas entre 1929 e 1979, distribuídas por diferentes tipos de periódicos 
6]. A partir desta data, a descoberta e a separação dos enzimas conheceu uma grande expansão, à qual não foi alheio Kurt Jacobsohn e os seus seguidores. O estudo enzimológico que o grupo realizou, incidiu sobre vários enzimas com particular incidência nas seguintes alcenoicases: a fumarico-hidratase (fumarase), a fumarico-amoniacase (aspartase) e as aconitases. Para além destes enzimas, a "escola" estudou também outro tipo de enzimas, as esterases, como a colinesterase, e ainda a tiaminase, a fosfatase [8-10], a urease [11, 12], a glicerofosfatase [13] e a tirosinase [14], e realizou também ensaios da actividade catalítica de alguns enzimas em condições fisiológicas, e em situações patológicas, causadas quer por doença, quer por lesões operatórias $[5,6]$.

Os enzimas que constituíram o cerne do programa de investigação, e nos quais o grupo mais se distinguiu, foram os seguintes: fumarase, aspartase, aconitases, colinesterase e tiaminase.

O enzima fumarase foi descoberto em 1919 por Einbeck e em 1921, Battelli e Stern demonstraram a sua existência, classificando-o como um enzima que catalisa a hidratação do ácido fumárico mediante a formação de ácido málico levógiro (I-malato) [5, 6]. Entre 1931 e 1937, com base nos estudos realizados no laboratório de Kurt Jacobsohn no IRC, confirmouse a existência deste equilíbrio, e o enzima incluiu-se noutro grupo enzimático passando a designar-se por fumárico-hidratase. Este resultado surgiu na sequência de vários estudos realizados no Instituto nos quais foram encontradas várias fumarases e poucas hidratases, e pelos conhecimentos que existiam na época sobre a importância do ciclo degradativo dos glúcidos [15-21]. Havia assim todo o interesse em alterar a nomenclatura enzimática, colocando a fumarase no grupo das alcenoicases, à semelhança da aspartase. A proposta foi internacionalmente aceite [22].

A partir de 1955 , no $3^{\circ}$ Congresso Internacional de Bioquímica realizado em Bruxelas, foi admitida a possibilidade de se formar uma Comissão Internacional de Enzimas, e então, a fu- marase, que a "escola" designou por Fumarico-Hidratase, continuou a ser uma das designações recomendadas pela Comissão embora o enzima fosse classificado noutra classe, a classe das hidro-liases. Trata-se de fazer a classificação do enzima que catalisa a reacção inversa: em vez da formação de I-malato a partir de fumarato, como a "escola" propôs, a nova classificação envolve a formação de fumarato e de uma molécula de água, a partir de I-malato. O enzima recebeu a designação de I-malato hidroliase (EC 4.2.1.2) [23].

Relativamente à aspartase, Kurt Jacobsohn seguiu a mesma via de raciocínio, realizou estudos análogos sobre o equilíbrio biocatalítico com os sistemas da aspartase e das aconitases em simultâneo com os da fumarase, levando-o a propor que o enzima que catalisava a reacção de transformação do ácido fumárico em ácido I-aspártico era do mesmo tipo da fumarase. Todavia, actualmente, o enzima passou a ser incluído no grupo das liases, l-aspartato amónia-liase (EC 4.3.1.1) [24] e aspartase passou a ser uma designação não recomendada. No entanto, a "escola" envolvendo-se neste raciocínio tentou resolver a hipótese, mas verificou que apenas o ácido fumárico sofre este tipo de fermentações, não tendo sido verificado outros exemplos de ácidos não saturados acessíveis a uma hidratação ou aminação enzimática [25, 26], atribuindo-se a isso o papel fisiológico altamente específico que o ácido fumárico tem no metabolismo celular.

O problema da degradação metabólica do ácido cítrico ocupava nesta época os bioquímicos do mundo inteiro e particularmente da Alemanha. A partir dos primeiros trabalhos de Martius e Knoop [27], em que estes autores assumiam que a fumarase seria o enzima actuante sobre o ácido cis-aconítico, os investigadores da "escola" de Jacobsohn envolveram-se no estudo desta problemática e as suas contribuições permitiram reforçar algumas ideias sobre reacções parciais envolvidas no ciclo dos ácidos tricarboxílicos proposto por Krebs em 1936 [28] e conduziram a "escola" ao estabelecimento de novos pressupostos sobre o mecanismo da biocatálise em geral ${ }^{5}$.
A colinesterase e a tiaminase, dois sistemas enzimáticos, eram na época sistemas cuja actividade se considerava estar directa ou indirectamente relacionada com a vitamina $\mathrm{B} 1$, que tinha um interesse clínico muito valorizado, em particular, pela secção de fisiologia do IRC da qual faziam parte os investigadores que adquiriam formação bioquímica no laboratório de Kurt Jacobsohn. Seria pois natural que a "escola" optasse por estabelecer uma linha de investigação para o estudo sistemático destes sistemas, procurando dar aos resultados obtidos uma explicação bioquímica [29] que servisse tanto aos médicos como aos bioquímicos do Instituto [30-35]. Foi provavelmente a investigação mais complexa realizada pelo grupo de investigação de Kurt Jacobsohn cujos resultados não foram significativamente expressivos para identificar estrutural e funcionalmente os dois sistemas enzimáticos.

No que respeita às investigações realizadas no âmbito do metabolismo lipídico, o grupo de Jacobsohn seguiu o mesmo esquema de análise estrutural de alguns enzimas envolvidos no metabolismo lipídico, bem como a influência exercida por vários iões em várias vias da lipogénese lipídica e outras vias relacionadas [36, 37], com o objectivo de obter um maior conhecimento acerca dos mecanismos regulatórios nos quais estes iões podiam influenciar o metabolismo dos ácidos gordos, triacilgliceróis, fosfolípidos, colesterol e acetoacetato, elementos representantes dos constituintes lipídicos celulares.

\section{Breves Conclusões}

A bioquímica, enquanto área de investigação, surgiu em Portugal em 1929, num instituto privado de investigação dirigido e frequentado por médicos, mas levou meio século a institucionalizar-se nas faculdades de ciências do país.

A presença de Kurt Jacobsohn na Faculdade de Ciências da Universidade de Lisboa estimulou o interesse pela bioquímica de alguns alunos da Licenciatura em Ciências Fisico-Químicas. Todavia, tudo parece indicar que a Secção de Química da Faculdade de Ciências de Lisboa não terá compre- 
endido a craveira científica de Kurt Jacobsohn, nem terá tirado partido da sua presença, no sentido de promover a investigação científica nesta área a partir dos finais dos anos 40. Apenas em 1964 pôde incluir a disciplina no curriculum da licenciatura em Ciências Físico Químicas.

A presença de Jacobsohn no IRC e na então Secção de Química da FCUL, apesar das dificuldades que possam ter existido, constituiu a base a partir da qual a bioquímica se foi lentamente consolidando, cristalizando-se numa licenciatura da especialidade, em 1982, na Faculdade de Ciências de Lisboa. Tendo sido, em Portugal, o primeiro investigador com formação especializada em bioquímica e o que primeiro assumiu a identidade profissional de bioquímico, a figura de Kurt Jacobsohn e a sua "escola" de investigação são, indubitavelmente, parte integrante da história da bioquímica em Portugal.

\section{Notas}

1 Bento da Rocha Cabral nasceu em Paradela de Guiães, concelho de Sabrosa. Casou no Brasil com Maria Jaymot e não deixou descendentes directos. Bento da Rocha Cabral viajava muito pelo estrangeiro, em particular pela Europa e pela América e desde sempre se mostrou sensível à ideia de deixar no seu País parte da sua riqueza destinada a obras de interesse colectivo. Para mais pormenores sobre as cláusulas testamentárias de Rocha Cabral consulte-se a obra, Ferreira de Mira, O Instituto de Investigação Científica Bento da Rocha Cabral (Coimbra, Imprensa da Universidade de Coimbra, 1926).

2 Rocha Cabral não conhecia pessoalmente Ferreira de Mira, mas conhecia o seu trabalho no Instituto de Química Fisiológica da Faculdade de Medicina de Lisboa, na vereação da Câmara Municipal de Lisboa, no Parlamento, onde foi deputado em três legislaturas, mas principalmente através da sua actividade jornalística. Ferreira de Mira, por várias vezes reclamara publicamente a dificuldade de se desenvolver a investigação científica em Portugal, já que no seu entender, reinava no país uma mentalidade alicerçada num anticientismo primário. Ferreira de Mira publicava artigos de opinião n'A Lucta e entre 1912 e 1922 defendeu insistentemente, a ideia do mecenato no sentido de se constituírem centros de investigação privados, com poderes e recursos para gerir a sua própria investigação, a exemplo dos Institutos Rockefeller e Carnegie, nos Estados Unidos.

3 Carl Neuberg foi considerado um dos bioquímicos alemães mais importantes da segunda geração provenientes de uma tradição associada à Química Orgânica. Foi um dos cientistas mais medalhados do seu tempo, de tal forma que foi criada uma medalha em seu nome pela American Society of European Chemists. Recebeu de Adolf Hitler a condecoração de herói da Pátria pelas suas contribuições científicas durante a la Guerra mas, apesar de ter sido nomeado três vezes pela Academia Sueca, nunca recebeu o Prémio Nobel. A sua obra realizada com a colaboração de vários investigadores e estudantes resume-se a cerca de 900 publicações efectuadas nos laboratórios onde esteve.

4 Estes enzimas catalisam a saturação da ligação dupla de diferentes alcenoicos existentes na natureza pela fixação de certos compostos minerais, como a água, bases azotadas, etc. São enzimas que intervêm na fermentação metabólica dos glúcidos, em conformidade com os esquemas de Szent-Györgyi e de Krebs, fazendo a transição para o metabolismo dos ácidos gordos e dos aminoácidos.

5 Estes trabalhos respeitantes ao ciclo do ácido cítrico, no qual Kurt Jacobsohn detectou reacções particulares, são referidos por Polonowski. M., Polonowski, Biochimie Médicale, Paris: Masson et Cie (1947) 447.

\section{REFERÊNCIAS}

[1] I. Amaral, "Na Vanguarda da Modernidade: o dinamismo sinergético de Marck Athias, Celestino da Costa e Ferreira de Mira na primeira metade do séc. XX", in R. Pita e A. L. Pereira, (ed.), Estudos do Século $X X$, Coim- bra: Imprensa da Universidade de Coimbra (2004) 263-282.

[2] I. Amaral, Annals of Science 63(1) (2006) 85-110.

[3] M. B. Ferreira de Mira, O Instituto de Investigação Científica Bento da Rocha Cabral, Coimbra: Imprensa da Universidade de Coimbra (1926).

[4] I. Amaral, R. E. Pinto e A. Carneiro, «La Recherche Biomédicale au Portugal —I'Héritage du IRC (1922-1953),» in R. Belot, M. Cotte e P. Lamard, (ed), La Technologie au Risque de I'Histoire, Paris: BERG International Éditeurs - Université de Technologie de BelfortMontbéliard (2000) 329-336.

[5] I. Amaral, As Escolas de Investigação de Marck Athias e de Kurt Jacobsohn e a Emergência da Bioquímica em Portugal, Dissertação de Doutoramento: Universidade Nova de Lisboa (2002).

[6] I. Amaral, A Emergência da Bioquímica em Portugal: as escolas de investigação de Marck Athias e de Kurt Jacobsohn, Textos Universitários de Ciências Sociais e Humanas, Lisboa: FCG/FCT (2006).

[7] J. M. Cruz, Homenagem a Kurt Jacobsohn, Lisboa: Instituto Rocha Cabral (1979) 3.

[8] K. Jacobsohn, F.B. Pereira, Comptes Rendues de la Société de Biologie de Paris, 107 (1931) 1168-1170.

[9] K. P. Jacobsohn, Biochemische Zeitschrift, 230 (1931) 304-311.

[10] J. M. Rosado, Revista da Faculdade de Ciências, 2 (1953) 15-22.

[11] K. P. Jacobsohn, M. Cruz, Archives Portuguaises des Sciences Biologiques, 7 (1945) 59-61.

[12] K. P. Jacobsohn, M. Cruz, Archives Portuguaises des Sciences Biologiques, 7 (1945) 73-75.

[13] K. P. Jacobsohn, M. Cruz, Archives Portuguaises des Sciences Biologiques, 7 (1945) 62-64.

[14] M. B. Ferreira de Mira; K. P. Jacobsohn, Separata do Livro da II $^{a}$ Reunião Biológica Portuguesa (1947) 338-342.

[15] K. P. Jacobsohn, M. Cruz, Comptes Rendues de la Société de Biologie de Paris 124 (1931) 94-96.

[16] K. P. Jacobsohn, Biochemische Zeitschrift 239 (1931) 449-455

[17] K. P. Jacobsohn, J. Tapadinhas, F. B. Pereira, Biochemische Zeitschrift, 249 (1932) 71-74.

[18] K. P. Jacobsohn, J. Tapadinhas, Recherches sur l'Équilibre du Système de la Fumarase, Lisboa: Instituto Ro- 
cha Cabral (1934).

[19] K. P. Jacobsohn, J. Tapadinhas, Comptes Rendues de la Société de Biologie de Paris 118 (1935) 1110-1112.

[20] P. Cunha, K. P. Jacobsohn, Comptes Rendues de la Société de Biologie de Paris 123 (1936) 609-610.

[21] K. P. Jacobsohn, Comptes Rendues de la Société de Biologie de Paris 124 (1937) 1028-1029.

[22] H. v. Euler, Chemie der Enzyme, 2, (1934), 533, 555.

[23] M. Florkin, E. Stotz, Comprehensive Biochemistry - Enzyme Nomenclature, Vol. 13, Amsterdam: Elsevier Publishing Company (1965) 166-167.

[24] M. Florkin, E. Stotz, Comprehensive Biochemistry - Enzyme Nomencla- ture, Vol. 13, Amsterdam: Elsevier Publishing Company (1965) 170-171.

[25] K. P. Jacobsohn, Biochemische Zeitschrift 282 (1935) 374-382.

[26] K. P. Jacobsohn, M. Soares, Enzymologia 1 (1936) 183-190.

[27] C. Martius, F. Knoop, Z. Physiol. Chem. 246 (1937) 1-6.

[28] H. A. Krebs, Perspectives in Biology and Medicine, 14 (1970) 154-170.

[29] K. P. Jacobsohn, Portugaliae Acta Biologica 1 (1945) 123-128.

[30] K.P. Jacobsohn,A. Cruz, J. Tapadinhas, Bulletin de la Société Portuguaise des Sciences Naturelles 14 (1943) 45-47.

[31] K. P. Jacobsohn, M. D. Azevedo, Archives Portugaises des Sciences Biologiques 9 (1947) 124-125.
[32] K.P. Jacobsohn, M. D.Azevedo, Comptes Rendues de la Société de Biologie de Paris 145 (1951) 1736-1738.

[33] K. P. Jacobsohn, M. D. Azevedo, Comptes Rendues de la Société de Biologie de Paris 146 (1952) 953-955.

[34] K. P. Jacobsohn, M. D. Azevedo, Enzymologia, 24 (1962) 123-128.

[35] K. P. Jacobsohn, M. D. Azevedo, Revista Portuguesa de Química 11 (1969) 121-125.

[36] K. P. Jacobsohn, M. D. Azevedo, Archives Portugaises des Sciences Biologiques 10 (1949) 86-88.

[37] R. Leal, R., M. P. Rodrigues, Archives Portugaises des Sciences Biologiques 17 (1972) 21-27.

\section{Actualidades Científicas}

. .

Nanopartículas na Cadeia Alimentar

Os cientistas pouco sabem ainda sobre como a libertação de algumas das mais de 2 milhões de toneladas de nanopartículas produzidas todos os anos irão afectar os organismos no meio ambiente. Um novo estudo revela que as minhocas Eisenia fétida podem ingerir nanopartículas de ouro do solo circundante, acumulando-as nos seus tecidos - uma descoberta com implicações significativas na cadeia alimentar (Environ. Sci. Technol., DOI: 10.1021/es101885w).

Os fabricantes de cosméticos, roupa e instrumentação médica incorporam nanopartículas nos seus produtos. Em condições de utilização normal, como por exemplo em lavagens, estes produtos libertam nanopartículas para as águas residuais, onde terminam como lamas residuais. Nos Estados Unidos e na Europa, os agricultores aplicam essas lamas residuais como fertilizante nos seus campos agrícolas.

O toxicologista ambiental Jason Unrine, da Universidade de Kentucky, Lexington, e seus colegas, procuraram saber se as nanopartículas aplicadas em campos agrícolas poderiam entrar na cadeia alimentar. "Uma vez que esperávamos que os nanomateriais se agregassem às partículas do solo, estávamos inicialmente muito cépticos sobre a possibilidade de captura dessas nanopartículas pelos organismos", referiu Unrine. Para confirmar, a equipa de Unrine misturou minhocas - organismos próximos da base da cadeia alimentar - com solo artificial contaminado com nanopartículas de ouro. "Usamos nanopartículas de ouro pelo facto de serem estáveis, insolúveis e facilmente detectáveis", afirmou Unrine. Após 28 dias, os investigadores examinaram os tecidos das minhocas para procurar vestígios das nanopartículas. Os cientistas utilizaram primeiro LA-ICP-MS (espectrometria de massa acoplada a um indutor de plasma com extracção por ablação a laser) para mapear a distribuição total de ouro nos tecidos das minhocas. Depois usaram uma técnica mais morosa, microespectroscopia de raios $X$ utilizando a radiação de sincrotrão, em regiões seleccionadas, para confirmar que o ouro estava na forma metálica e não em resíduos iónicos resultantes do processo de produção das nanopartículas. Unrine e colegas encontraram nanopartículas de ouro de 20 e $55 \mathrm{~nm}$ distribuídas por todo o corpo das minhocas, tendo as concentrações mais elevadas sido encontradas no intestino. Embora as nanopartículas de ouro não tenham afectado significativamente a mortalidade das minhocas, as minhocas expostas reduziram a sua descendência até $90 \%$. Unrine planeia estudos futuros para examinar mais detalhadamente as respostas biológicas das minhocas a nanomateriais.

"Este estudo fornece a melhor evidência até à data sobre a transferência de nanopartículas do solo para os tecidos", refere Rubert Hurt, um engenheiro ambiental da Universidade de Brown, que é da opinião também de que este estudo pode ter implicações significativas: "As nanopartículas são encontradas tipicamente em baixas concentrações no ambiente, mas irão ter um potencial muito maior para afectar a saúde humana se bioacumularem na cadeia alimentar."

(Adaptado do artigo de 07/10/2010 de Laura Cassiday: Nanoparticles Worm Their Way Into The Food Web, Chemical \& Engineering News, DOI:10.1021/ CEN093010144555)

Helder Gomes (bquimica@ipb.pt) www.spq.pt 